\title{
Bridging The Knowing/Doing Gap To Create High Engagement Work Cultures
}

\author{
Dr. Fredricka F. Joyner, Indiana University East, USA
}

\begin{abstract}
The magnitude of investment made by U.S. organizations in the training and development of individuals is significant, as business leaders strive to implement strategies to create high engagement work cultures. Most initiatives are training-based and aimed at managers, and enjoy limited success. The question then arises, are the managers failing to grasp what they are taught, or are they failing to implement it? Through a qualitative analysis of both student/employee and management/employer responses regarding actions and behaviors linked to high engagement work cultures, I establish strong support for the argument that managers do in fact know what factors create high engagement environments, as do their employees; lack of training is not the culprit. Hence, I explore management perceptions in order to discover what barriers prevent them from implementing what they know is necessary. By comparing perceived barriers to known qualities of a high engagement work cultures, I suggest strategies for reducing barriers and increasing success. These strategies can then be used to identify the optimal arenas in which organizations can direct investments in order to provide appropriate resources and support to managers responsible for creating high engagement work cultures. This small yet disciplined qualitative research study sets the stage for future research studies.
\end{abstract}

Keywords: Employee Engagement; Work Culture; Barriers To Engagement

\section{INTRODUCTION}

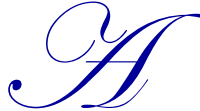

s the importance of creating high engagement workplaces becomes increasingly well-quantified, a growing number of organizations strive to implement engagement strategies and initiatives. Many of these are training-based initiatives designed to intervene at the individual manager level, built on the assumption that if managers are so important in creating high engagement workplaces, then they must be trained.

The magnitude of the investment made by U.S. organizations in the training and development of individuals is significant. The American Society for Training and Development's (ASTD) 2012 State of the Industry Report found that in 2011 U. S. organizations spent $\$ 146 \mathrm{~B}$ on employee learning (Miller, 2012). With the recovering economy, training expenditures jumped another 12\% in 2012 (Hollon, 2013). The subset of this investment that focuses specifically on leadership development is also expected to rise over the next 12 months, with $37 \%$ of North American companies reporting that they expect to increase their investments in this area (Right Management, 2013). Of course, all of this training is not focused on manager behaviors and actions linked to high engagement workplaces, but the numbers do speak to the prevailing belief in the efficacy of training in shifting workplace behaviors.

The following paper describes a set of small studies designed to develop a deeper understanding of the factors influencing the extent to which managers incorporate the behaviors and actions linked to increased employee engagement into their day-to-day management practice. This deeper understanding provides a useful context within which to explore how investments at the individual skill development level can best be leveraged. The first section describes the current workplace engagement gap, followed by the knowing/doing gap, which describes a two-part qualitative research study undertaken to develop a better understanding of the variables creating this incongruity. This small yet disciplined research study sets the stage for future research studies that are more comprehensive in nature. The paper concludes with discussion of strategies organizations can use to bridge the gap between 
recognized best practices for supporting high engagement workplaces and frequent practices linked with low employee engagement.

\section{THE WORKPLACE ENGAGEMENT GAP}

\section{The Strategic Imperative For High Engagement Workplaces}

Shifts in the external environment. The interplay between the increasing complexity and competitiveness of the external environment and contracting labor forces in the United States and European Union are creating a challenging set of workplace dynamics. Ever-changing technology, globalization, environmental concerns, resource constraints, and a host of other issues are escalating complexity and competitiveness such that achieving business results is increasingly challenging. Meanwhile, talent pools in these two regions are shrinking. Fishman (1998) predicts that, in a few short years, there may be as much as a $25 \%$ increase in demand for 35-45 year old workers in the United States but 15 percent fewer Americans in the age group. The Employment Policy Foundation (2001) anticipates that by 2030 there could be 20 percent more jobs than workers in the United States. The European Union is "facing unprecedented demographic changes (an ageing population, low birth rates, changing family structures, and migration)" (European Commission, n.d., para. 1). In 2009, the median age of the population was 40.6, and it is projected to reach 47.9 by 2060 . There is a clear trend toward steep increases in 50+ workers with the number of people aged 60 and above rising by more than two million every year coupled with a decline in the younger cohorts (European Commission, 2011).

While the economy over the past few years has caused some easing of competitive pressure for talent, there has been no change in these fundamental demographic patterns. There is little doubt that over the next several decades the business environment will continue to become more challenging, the demand for talent will continue to increase, and, based on fundamental demographic patterns, the amount of available talent will continue to decrease. In the face of the dynamic tension caused by these trends, attracting and retaining top talent has become increasingly important for organizational success and, for many companies, a strategic imperative. In discussing the results of a survey of over 700 clients of the global consultancy PI Worldwide, Harris concluded that "given today's dynamic, global, hypercompetitive marketplace and the accompanying scarcity of talent, it's clear companies are increasingly recognizing the need to identify, develop and retain high-caliber leaders" (2008, para.1).

Over the past several years, the development of high engagement workplaces has emerged as a strategic response to address both shifting workforce demographics and the need to achieve results in a challenging environment. High engagement workplaces have been linked to the ability to attract and retain top performers, and an increase in the percentage of engaged employees has been closely linked to the ability to achieve business results (Buckingham \& Coffman, 1999; DiRomualdo, n.d.; Rucci, Kirn \& Quinn, 1998; Wilson Learning Worldwide Inc., n.d.).

Attributes and dynamics of a high engagement workplace. There are many variations on the definition of an engaged employee (Ames, 2012; Buckingham \& Coffman, 1999; Management Study Guide, n.d.; Kruse, 2012; O'Boyle \& Harter, 2013; Williams, 2010; Wilson Learning Worldwide Inc., n.d.). Prior to beginning this study, an Internet survey for definitions for "engaged employee" was conducted. Over 25 definitions were reviewed, and from those the following general definition was developed. An engaged employee is a consistently high performer who is committed to the organization and willingly invests his or her talent and discretionary effort.

Numerous publications have identified various attributes of a high engagement workplace ${ }^{1}$, with strong common themes cutting across frameworks. For example, high engagement workplaces often: provide employees with clear expectations coupled with the support necessary to achieve them; recognize the importance of and strive for effective person-job fit; are recognition-rich; provide ample access to development opportunities and career growth; give opportunities for "having a voice" or influence; draw a meaningful line of sight between daily work and larger mission; and have a strong two-way flow of feedback.

\footnotetext{
${ }^{1}$ For example, see Ames, 2012; Buckingham \& Coffman, 1999; DiRomualdo, n.d.; Management Study Guide, n.d.; O’Boyle \& Harter, 2013; Rucci et al., 1998; Ryan Group Inc., n.d.; Scholtes, 1998; Williams, 2010; and Wilson Learning Worldwide Inc., n.d.
} 
While a variety of core attributes of engaged workplaces have been identified, a fundamental theme present in virtually all of these models is the ability of the local manger to create a relationship-rich workplace (Baumruk, 2006; Buckingham \& Coffman, 1999; Dale Carnegie Training \& MSW Research, 2012; Lupfer, 2013). A study recently released by MSW Research and Dale Carnegie Training once again identifies the critical role of the local manager: "A national representative sample of 1,500 employees was surveyed. [The study] revealed that although there are many factors that impact employee engagement, there are three key drivers: relationship with immediate supervisor; belief in senior leadership; and pride in working for the company." Individuals surveyed stated that "the personal relationship with their immediate supervisor is the key." The study concluded that "the attitude and actions of the immediate supervisor can enhance employee engagement or can create an atmosphere where an employee becomes disengaged" (Dale Carnegie Training \& MSW Research, 2012: 2). As this illustrates, managers who can competently build relationships bring tangible value to their organizations. The steps of the critical relationship building process have been mapped out in the Connection Circle model (Figure 1). Building self-awareness is at the core of relationship-building, because greater self-awareness allows an individual to make a broader range of selfmanagement choices. Likewise, a broader repertoire of choices creates more opportunities for engaging others, and effectively engaging others supports the achievement of business results.

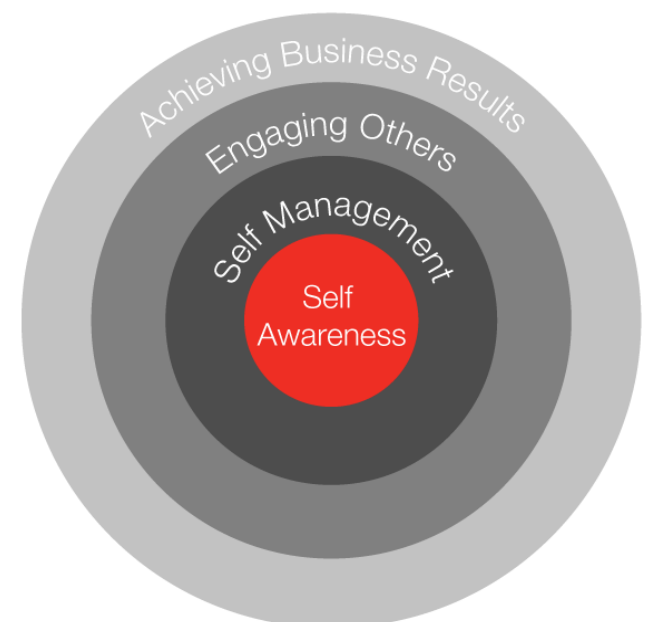

Figure 1. Connection Circle

In addition to identifying the specific attributes of high engagement workplaces and the fundamental role of the local manager, the studies listed above have established a strong connection between engaged employees and business results. The critical impact of engagement on business results has been clear for some time. The importance of the relationship between engagement and business results first appeared on the scene in a 1998 publication in the Harvard Business Review, "The Employee-Customer-Profit Chain at Sears," describing rigorous work at Sears to identify and measure the drivers of future financial performance (Rucci et al., 1998). The authors describe the development of a system to produce dependable information about causation that could be used as a proactive management tool. What they discovered is that "a 5 point improvement in employee attitudes will drive a 1.3 point improvement in customer satisfaction, which in turn will drive a $0.5 \%$ improvement in revenue growth" (91). Over a decade of solid research, the face validity of which has been confirmed by experiences of individuals in organizations of every size and type, has followed from this seminal study. Through this collective body of work, a set of relationships - in which relationship with the leader drives employee engagement, which drives customer satisfaction, which in turn drives business results - has been quantified (Figure 2). 

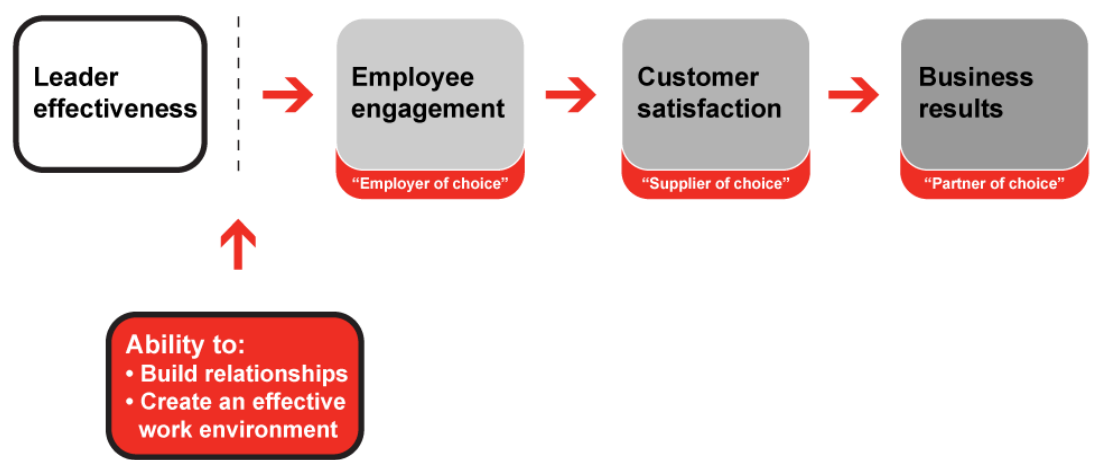

Figure 2. Strategic Relationship Chain

Research has also identified the costly consequences that occur when the strategic relationship chain is not in place. These cost come in several forms, most notably expensive voluntary turnover and loss of the benefit associated with discretionary effort. The cost of turnover is significant, estimated at one- to two years' pay and benefits (Ahlrichs, 2003). More significant yet is the cost associated with the absence of discretionary effort. Discretionary effort can be defined as "employee willingness to go 'above and beyond' the call of duty, such as helping others with heavy workloads, volunteering for additional duties, and looking for ways to perform the job more effectively" (Corporate Executive Board, 2004: 4). Gallup research (Krueger \& Killham, 2006) has helped to describe the magnitude of this cost in terms of three groups of employees, whom they identify as engaged, notengaged, and actively disengaged.

[Engaged employees] work with passion and feel a profound connection to their company. They drive innovation and move the organization forward. [...] Not-engaged employees are essentially 'checked out.' They're sleepwalking through their workday, putting time - but not energy or passion - into their work. [...] Actively disengaged employees aren't just unhappy at work; they're busy acting out their unhappiness. Every day, these workers undermine what their engaged coworkers accomplish. (1)

Gallup has determined that, in the U.S. workforce, the ratio of engaged to actively disengaged employees is approximately 2:1, while high engagement organizations boast ratios of more than 9:1. They estimate the cost of active disengagement within the U.S. workforce to be \$450-\$550B (O'Boyle \& Harter, 2013). The gap between individual application of discretionary effort and simply meeting minimal expectations can be thought of as the zone of employee value-added (Figure 3). When present, employee value-added can provide a significant competitive edge.

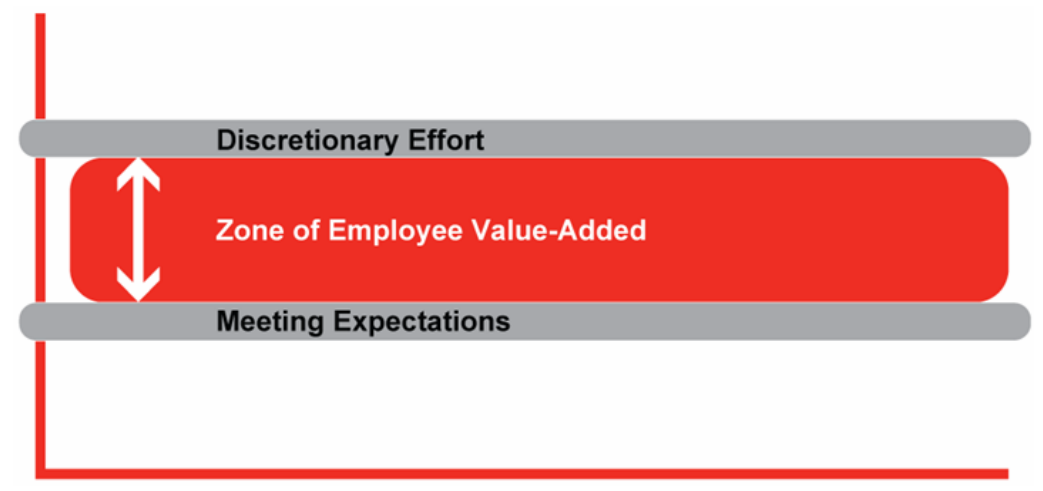

Figure 3. Discretionary Effort Zone

\section{The Prevalence of Low Engagement Workplaces}

Despite the robust research- and experience-based case for high engagement workplaces outlined above, they are far from the norm. 
Students' perspective. As a part of an introductory assignment in an undergraduate organization behavior course, students were asked to respond to the following: Identify five words that describe aspects of your worst work experiences. All of the words submitted were combined and entered into Wordle ${ }^{\mathrm{TM}}$ (Fienberg, 2011), thus creating a collective "word cloud." The word cloud synthesized the individual experiences, represented by the words submitted, into one image by making words mentioned more often larger. The resulting word cloud (Figure 4) illustrates how a group of individuals, relatively new to the world of work, are already able to draw on their own experiences to clearly describe the attributes of a low engagement workplace.

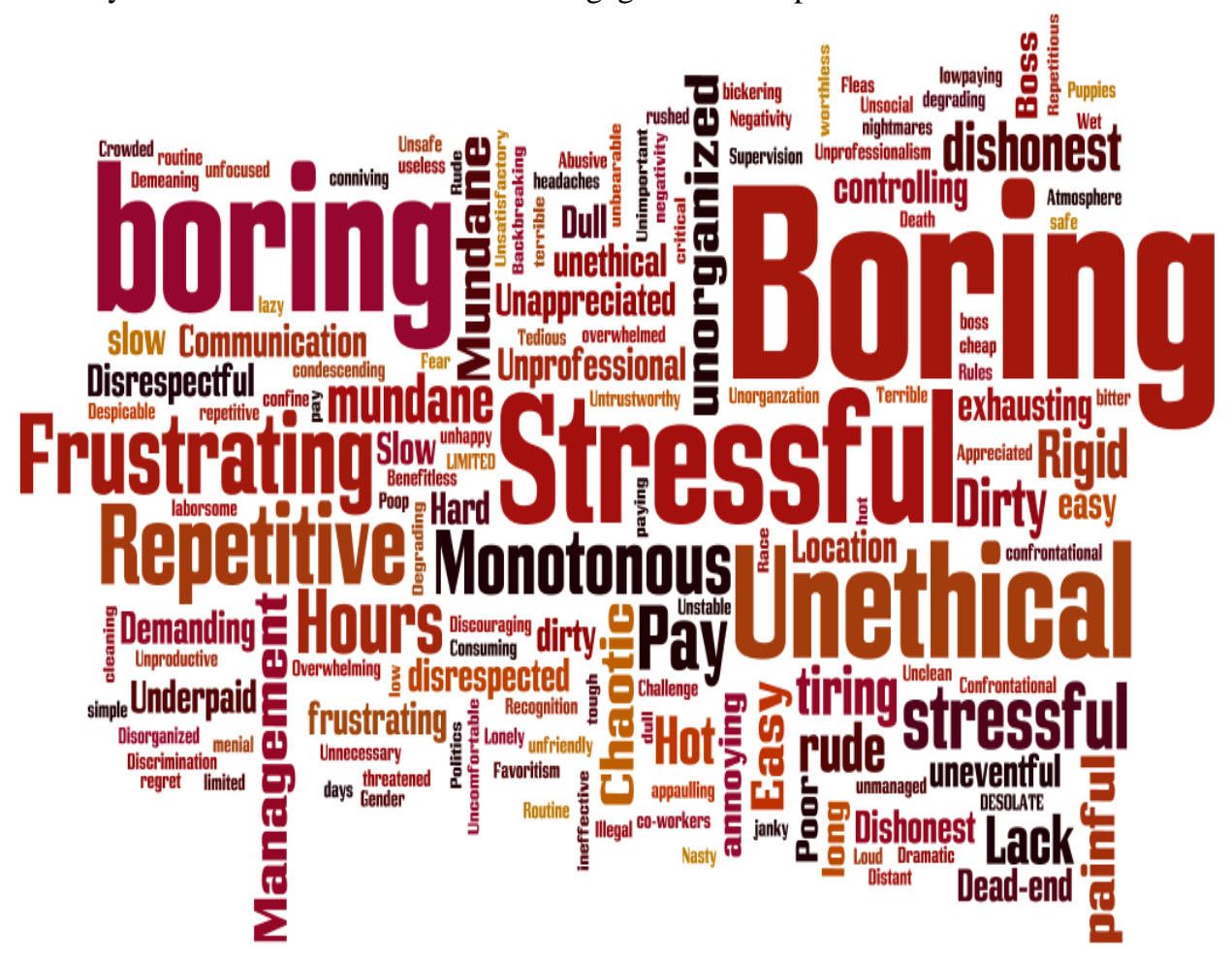

Figure 4. Worst Work Experience Word Cloud

Employees' perspective. For many years I have facilitated a leadership development program that includes unstructured presentations by senior leaders. In a recent session, the senior leader who was presenting went "off script" and spontaneously asked the group, "How many of you have had a toxic boss?" Almost every hand in the group shot up. Intrigued by this response, I conducted a literature review that confirmed the response I had seen from the group in the leadership development program. A cursory review quickly yielded over fourteen pages of citations with the academic, professional, and popular press all well-represented. In addition to books and articles, there was a plethora of blogs, YouTube videos, discussion forums, workshops, training, and self-help materials where stories were shared and tips and coping mechanisms exchanged. Terms surfaced such as "workplace bully," "horizontal violence," "shifty snipers," and "dangerous leaders," to name a few. I found many different approaches to the topic. For example: (1) in their 2009 book, Toxic Workplace!, Kusy and Holloway describe how to identify and work effectively with toxic personalities; (2) a report on Toxic Boss Syndrome that aired on Good Morning America (Roberts \& Johnson, 2010) cites research finding that over 1/3 of all American workers say they have been bullied on the job; (3) in his 2008 thesis, Andrew Schmidt developed and validated a Toxic Leadership Scale that he believes can predict employee outcomes such as turnover and job satisfaction; (4) a research brief published in Academy of Management Perspectives explores the ways in which organizational factors contribute to bullying; (5) an article in Woman's Day (Klavan, 1990) shares information on topics such as "where to go for help" and "when quitting is the answer."; and (6) an article in BusinessWeek (2008, August), entitled Toxic Bosses: How to Live with the S.O.B., takes an even more direct approach through tips such as "hanging up the phone when the manager begins yelling." 
The student and business perspectives offered represent almost two decades of research and experience supporting the critical importance of employee engagement and the connections between leader behaviors, employee engagement, customer satisfaction, and bottom-line business results, as well as evidence of the abiding prevalence of low engagement workplaces.

\section{THE KNOWING/DOING GAP}

The solid, bottom line impact of a high engagement workplace is well quantified. Yet, as illustrated, many managers have not integrated the actions clearly linked with heightened feelings of engagement among employees into their practice. In their 2010 report, The Role of Employee Engagement in the Return to Growth, the Corporate Executive Board reported that, while the overwhelming percentage of leaders recognize employee engagement practices directly impact the success of their business, less than $25 \%$ have an engagement plan or strategy in place. Through the following research questions, I explore the incongruity between recognizing the importance of employee engagement and yet not taking action to increase levels of engagement:

- Is the incongruity due to managers not knowing what to do? If not,

- What are the barriers that prevent managers from doing what they know?

Part one of the following study explores the first question, Do managers know what to do?, and finds that the managers who participated are familiar with the elements that have been clearly linked to a heightened sense of engagement among employees. In other words, they know what to do. Part two explores the perceived barriers that prevent managers from more fully implementing these elements of engagement.

\section{Part One: Do Managers Know What to Do?}

To gain insight into the extent to which the elements that comprise a high engagement workplace are broadly known, two studies were conducted. The participant group for the first study was college students and for the second study was working managers.

Method. The college student study was conducted to answer the question: What do students know about workplace engagement prior to being introduced to specific content on the topic? Participants in this study were students in sections of a 300-level organization behavior course (offered during the 2010-2011 academic year) that included content on employee engagement. All of the approximately 80 students who participated in the study had work experience; some also had supervisory or managerial experience. Each student was asked to respond to the following: Identify five words that describe aspects of your best work experiences.

The manager study was conducted to answer the question: Do managers know the elements that comprise a high engagement workplace? A "free list" technique was used as the method for systematic elicitation of ideas. In this technique short, open-ended questions are used to generate relevant items and ideas. The frequency of mention and the order in which items are mentioned is an indicator of the items salience (Ryan \& Bernard, 2000). The study was designed as an opening activity during a four-day training session focused on the development of management skills such as conflict management, change implementation, performance management, and coaching. Between January, 2009 and December, 2011, sixteen sessions were held. The study included 250 participants (frontline through mid-level managers), representing various business units of a global Fortune 500 company. At the outset of the activity, the general definition of an engaged employee, An engaged employee is a consistently high performer who is committed to the organization and willingly invests his or her talent and discretionary effort, was reviewed. Participants were arranged in groups of 6-8 and asked to discuss and develop a group list of responses to the following question: What are the elements that contribute to feelings of heightened engagement among employees? In developing their responses, participants were encouraged to think broadly. To conclude the activity, the lists from each small group were shared and a composite large group list, with minimal duplication of items, was developed.

Results. All of the words submitted in the student study were combined into a single list and entered into Wordle"TM (Fienberg, 2011), thus creating a collective "word cloud" (Figure 5). 


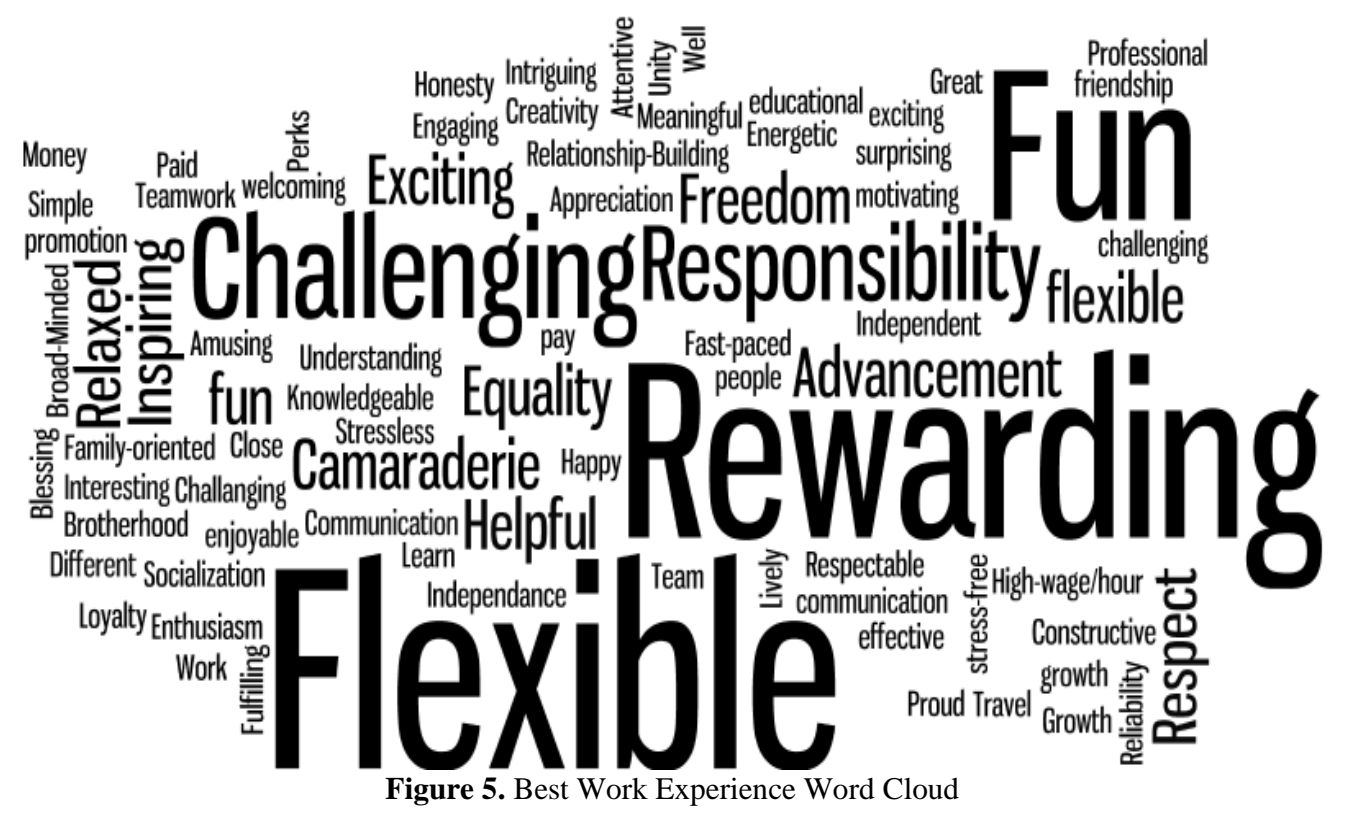

The 16 composite lists that resulted from the manager study activity were combined into one comprehensive list that included 209 items. Key patterns and themes were induced using an inductive coding technique in which initial themes were derived from the literature review (described in this paper) with additional refinement based on interpretive analysis. The result of this disciplined qualitative process was the identification of 19 thematic categories (Table 1).

Table 1. Identified Elements of Engagement

\begin{tabular}{lcc}
\multicolumn{1}{c}{ Element Category } & $\begin{array}{c}\text { Number of Times } \\
\text { Item Appeared }\end{array}$ & $\begin{array}{c}\text { \%otal } \\
\text { (n= 209) }\end{array}$ \\
\hline Opportunities to participate & 29 & $14 \%$ \\
Meaningful work & 20 & $10 \%$ \\
An environment of mutual trust and respect & 19 & $9 \%$ \\
Recognition and appreciation & 18 & $9 \%$ \\
Clear goals and expectations & 18 & $9 \%$ \\
Opportunities for skill and career development & 15 & $7 \%$ \\
Feel valued and known as a person & 13 & $6 \%$ \\
Having the resources/tools necessary to do the job & 13 & $6 \%$ \\
Being part of a team & 11 & $5 \%$ \\
Leaders who are role models & 9 & $4 \%$ \\
Opportunities to do work that is a good fit with skills and interests & 8 & $4 \%$ \\
Transparent, inclusive information sharing & 7 & $3 \%$ \\
Constructive, developmental feedback & 7 & $3 \%$ \\
Leaders who listen & 7 & $3 \%$ \\
An environment of accountability and responsibility & 5 & $2 \%$ \\
Being able to see a future with the company & 4 & $2 \%$ \\
Connections to customers & 3 & $1 \%$ \\
Work/life balance & 2 & $1 \%$ \\
Fun & 1 & $5 \%$ \\
\hline
\end{tabular}

Analysis. A process was developed to evaluate the results of the two studies (student and manager) and develop a response to the research question, Do managers know the elements that comprise a high engagement workplace? First, reviews of literature and practice field were conducted to identify actively used frameworks delineating key elements of engagement. Of these, six robust and research-based frameworks were selected, which together provide a balance of research and practitioner perspectives. The frameworks, chosen based on their individual credibility and their collective balance of research and practitioner perspectives, include: 
- Wilson Learning Worldwide: A global consultancy that, since 1965, has focused its practice on human performance improvement, Wilson Learning Worldwide is widely recognized for its consulting expertise as well as for its applied research and white papers related to human performance improvement. Its position paper, Employee Engagement: The Leader's Role (Wilson Learning Worldwide Inc., n.d.), identifies the key elements of a culture of engagement as follows: (1) Opportunity enables employees to emotionally connect with something important; (2) Personal accountability provides clear expectations and motivates employees to give their best; (3) Validation tells employees that they matter and have a valued place in the organization; (4) Inclusion provides employees with information and offers them a chance to express thoughts and feelings; and (5) Connectedness creates a sense of trust and support, where employees experience mutual interest and shared responsibility.

- $\quad$ The 12 Questions: Buckingham and Coffman's book, First, Break All the Rules (1999), conclusively quantifies the link between employee opinion and business performance. Their comprehensive study, which initially included over 80,000 managers from 400 companies, identified and tested 12 questions (known as the Q12) that measured the strength of a workplace. The authors defined a strong workplace as capable of attracting and retaining top talent; in other words, an engaging workplace. Since the results of their initial poll were published in 2006, Gallup has continued to test and confirm the connection between the elements of engagement measured by the Q12 and bottom line business results. The Q12, which have become the gold standard for describing an engaging work environment, are: (1) Do I know what is expected of me at work; (2) Do I have the materials and equipment I need to do my job right; (3) At work, do I have the opportunity to do what I do best every day; (4) In the last seven days, have I received recognition or praise for doing good work; (5) Does my supervisor, or someone at work, seem to care about me as a person; (6) Is there someone at work who encourages my development; (7) At work, do my opinions seem to count; (8) Does the mission/purpose of my company make me feel my job is important; (9) Are my co-workers committed to doing quality work; (10) Do I have a best friend at work; (11) In the last six months, has someone at work talked to me about my progress; and (12) In the last year, have I had opportunities at work to learn and grow?

- Next Generation Consulting: This interdisciplinary consultancy focused on preparing organizations and communities to be successful in the future context was founded by Rebecca Ryan, an author, economist, and futurist well known for her deep understanding of issues related to engaging the millennial generation. Based on this knowledge, Next Generation Consulting developed the following framework (DiRomualdo, n.d.) that articulates elements of engagement related to millennial workers: (1) Enrichment provides opportunities for growth - providing staff with a rich work and learning environment - and the tools and support they need to do the work they like most and are best at; (2) Appreciation gives everyone their fair share of reward and recognition - making sure that everyone who contributes to success is rewarded and recognized commensurately; (3) Membership builds bonds among workers and with the company developing rich person-to-person connectedness and belonging that individual employees share with others within or affiliated with an organization; (4) Meaning makes the mission purposeful - giving employees something they can believe in, something that gives their work and their lives meaning - something that involves a higher purpose; (5) Voice gives workers a say in the strategy of the business - giving them large degrees of discretion to act in pursuing the goals of the organization and trusting them to exercise their discretion widely; and (6) Harmony creates and sustains work-life balance - maintaining a work environment that allows staff to perform at peak without compromising their personal priorities and interests.

- $\quad$ The Leader's Handbook: Authored by internationally known author, lecturer, and consultant Peter R. Scholtes, The Leader's Handbook outlines seven "policies, practices, and environmental factors related to next millennium leadership" (1998: 383): (1) clear, constant, ennobling purpose; (2) opportunities to learn and grow; (3) continuous improvement of methods and processes; (4) mutual respect and trust; (5) frequent communication and access to information; (6) sense of community; and (7) participation.

- Glassdoor: This employer rating site has access to a large amount of data related to work preferences. Their 2014 Employee Choice Awards survey surfaced six themes that cut across the "most beloved companies" (Baer, 2013): (1) importance of mission - people feel most satisfied with the work when they find it deeply meaningful; (2) importance of collegiality - friendship among colleagues makes everybody more engaged; (3) challenging work - people want to expand their skill sets on the way to mastery; (4) meaningful advancement - people need to feel a sense of progress; (5) confidence in senior leaders - confidence and 
transparency reduce volatility, which encourage bold thinking; and (6) perks - people must be paid well to feel secure enough to do good work.

- The Ryan Group, Inc.: This consultancy specializes in assessment instruments. Their Employee Engagement Assessment (Ryan Group Inc., n.d.) is designed to measure the following five employee engagement categories: (1) organizational attachment; (2) personal involvement; (3) valued contribution; (4) distributive fairness; and (5) quality and customer orientation.

Next, the elements of engagement delineated in these six frameworks were compared and combined to create a general summary framework (Table 2) comprised of nine key elements of engagement.

Table 2. Summary Framework

\begin{tabular}{|c|c|c|c|c|c|c|}
\hline $\begin{array}{l}\text { Summary } \\
\text { Framework }\end{array}$ & $\begin{array}{l}\text { Wilson } \\
\text { Learning }\end{array}$ & Q 12 & $\begin{array}{c}\text { Next } \\
\text { Generation } \\
\text { Consulting } \\
\end{array}$ & $\begin{array}{c}\text { Leader's } \\
\text { Handbook }\end{array}$ & Glassdoor & $\begin{array}{l}\text { The Ryan } \\
\text { Group, Inc. }\end{array}$ \\
\hline $\begin{array}{l}\text { Design of the job } \\
\text { and the work } \\
\text { processes }\end{array}$ & & Job fit & & $\begin{array}{l}\text { Continuous } \\
\text { improvement of } \\
\text { methods and } \\
\text { processes }\end{array}$ & $\begin{array}{l}\text { Challenging } \\
\text { work }\end{array}$ & $\begin{array}{l}\text { Quality and } \\
\text { customer } \\
\text { orientation }\end{array}$ \\
\hline $\begin{array}{l}\text { Clear work } \\
\text { expectations, } \\
\text { feedback, and } \\
\text { support resources }\end{array}$ & $\begin{array}{l}\text { Personal } \\
\text { accountability; } \\
\text { Connectedness }\end{array}$ & $\begin{array}{l}\text { Expectations; } \\
\text { Feedback; } \\
\text { Necessary } \\
\text { resources }\end{array}$ & & & & $\begin{array}{l}\text { Distributive } \\
\text { Fairness }\end{array}$ \\
\hline $\begin{array}{l}\text { Opportunities for } \\
\text { training and } \\
\text { development }\end{array}$ & & $\begin{array}{l}\text { Opportunities } \\
\text { for development }\end{array}$ & Enrichment & $\begin{array}{l}\text { Opportunities to } \\
\text { learn and grow }\end{array}$ & $\begin{array}{l}\text { Meaningful } \\
\text { advancement }\end{array}$ & \\
\hline $\begin{array}{l}\text { Ample recognition } \\
\text { and appreciation }\end{array}$ & Validation & Recognition & Appreciation & & & $\begin{array}{l}\text { Valued } \\
\text { contribution }\end{array}$ \\
\hline $\begin{array}{l}\text { Positive, high } \\
\text { quality connection to } \\
\text { the work group and } \\
\text { the organization }\end{array}$ & Connectedness & $\begin{array}{l}\text { Opportunities to } \\
\text { work with } \\
\text { quality co- } \\
\text { workers }\end{array}$ & Membership & $\begin{array}{l}\text { Mutual respect } \\
\text { and trust; } \\
\text { A sense of } \\
\text { community }\end{array}$ & Collegiality & $\begin{array}{l}\text { Organizational } \\
\text { attachment }\end{array}$ \\
\hline Meaning & Opportunity & $\begin{array}{l}\text { Connection to } \\
\text { Mission }\end{array}$ & Meaning & Purpose & Mission & \\
\hline $\begin{array}{l}\text { Opportunities to } \\
\text { participate/ } \\
\text { influence }\end{array}$ & Inclusion & Influence & Voice & Participation & & $\begin{array}{l}\text { Personal } \\
\text { involvement }\end{array}$ \\
\hline $\begin{array}{l}\text { Communication-rich } \\
\text { environment }\end{array}$ & Inclusion & & & $\begin{array}{l}\text { Frequent } \\
\text { communication } \\
\text { and access to } \\
\text { information }\end{array}$ & $\begin{array}{l}\text { Confidence in } \\
\text { senior leaders; } \\
\text { Transparency }\end{array}$ & \\
\hline
\end{tabular}


Finally, the elements of engagement identified by the students and the managers were compared to the summary framework (Table 3). As illustrated, the managers identified elements of engagement related to each component of the summary framework. Additionally, 12 of the 14 key words from the students' word cloud map directly to the summary framework.

Table 3. Comparison Matrix

\begin{tabular}{|c|c|c|}
\hline Summary Framework & $\begin{array}{c}\text { Managers' Identified Elements of } \\
\text { Engagement }\end{array}$ & $\begin{array}{c}\begin{array}{c}\text { Students' Attributes of Best Work } \\
\text { Experiences }\end{array} \\
\end{array}$ \\
\hline Design of the job and the work Processes & $\begin{array}{l}\text { - Work that is a good fit with skills } \\
\text { and interests } \\
\text { - } \quad \text { Connections to customers }\end{array}$ & - $\quad$ Flexible \\
\hline $\begin{array}{l}\text { Clear work expectations, feedback, and } \\
\text { support resources }\end{array}$ & $\begin{array}{ll}\text { - } & \text { Clear goals and expectations } \\
\text { - } & \text { Resources and tools necessary to do } \\
\text { the job } \\
\text { - }\end{array}$ & $\begin{array}{ll}- & \text { Helpful } \\
- & \text { Equality }\end{array}$ \\
\hline $\begin{array}{l}\text { Opportunities for training and } \\
\text { development }\end{array}$ & $\begin{array}{l}\text { Opportunities for skill and career } \\
\text { development } \\
\text { - } \quad \text { See a future with the company }\end{array}$ & $\begin{array}{ll} & \text { Challenging } \\
- & \text { Advancement } \\
\end{array}$ \\
\hline Ample recognition and appreciation & - $\quad$ Recognition and appreciation & - $\quad$ Rewarding \\
\hline $\begin{array}{l}\text { Positive, high quality connection to the } \\
\text { work group and the organization }\end{array}$ & $\begin{array}{ll}\text { - } & \text { Mutual trust and respect } \\
\text { - } & \text { Feel valued and known as a person } \\
\text { - } & \text { Being part of a team }\end{array}$ & $\begin{array}{ll}\text { - } & \text { Camaraderie } \\
\text { - } & \text { Respect } \\
\end{array}$ \\
\hline Meaning & • $\quad$ Meaningful work & $\begin{array}{ll} & \text { Rewarding } \\
\text { - } & \text { Inspiring }\end{array}$ \\
\hline Opportunities to participate/influence & - $\quad$ Opportunities to participate & $\begin{array}{ll}- & \text { Freedom } \\
- & \text { Responsibility }\end{array}$ \\
\hline Communication-rich environment & $\begin{array}{ll}\text { - } & \text { Transparent, inclusive information } \\
\text { sharing } \\
\text { - } \quad \text { Leaders who listen }\end{array}$ & \\
\hline Work/life balance & • $\quad$ Work/life balance & - $\quad$ Flexible \\
\hline
\end{tabular}

Conclusion. This study was conducted to answer the question: Do managers know the elements that comprise a high engagement workplace? The comparison of the elements identified by the managers to the summary framework created based on expert practitioner models provides conclusive evidence that managers know the elements that comprise a high engagement workplace. In fact, results from the student study indicate that individuals have a fundamental understanding of these elements well before they step into a managerial role.

\section{Part Two: Are There Barriers to Doing?}

The conclusions drawn from Part 1 of the study lead to a subsequent pair of questions:

- If managers know the elements of engagement, what are their perceptions related to barriers that prevents them from incorporating these types of actions and activities more fully into their daily management practice?

- $\quad$ Are the growing multitude of training initiatives focused on manager actions related to high engagement workplaces an effective intervention for reducing barriers identified?

Method. To address the questions, a study was imbedded into the management training session described above to determine perceived barriers to implementing the engagement strategies identified by the first study. In the second study, a methodology based on systematic elicitation through the generation of a free list was once again used. A one-question written survey was distributed to individual participants after participation in a training module on creating an engaging work environment, containing the following question: From your perspective as a manager, 
what do you see as barriers (if any) to incorporating these types of actions and activities into your day to day management practice? Between April, 2011 and February, 2012, two hundred managers completed the written survey. Responses were broken down into 221 separate comments. A disciplined inductive coding technique was again used to perform a content analysis that identified key patterns and themes.

Results. A small number of comments indicated that there are no barriers to more fully incorporating engagement activities and another small number of comments identified "lack of training" as a barrier. Beyond the most infrequent comments, 13 thematic categories emerged from the content analysis of the remaining 201 comments. The headings for the 13 thematic categories identified are listed in Table 4 (along with the infrequent comments). The table also includes the number of times an item appeared and the percentage of the total items that number represents. Perceived barrier category headings are listed in descending order.

Table 4. Perceived Implementation Barriers

\begin{tabular}{lcc}
\hline \multicolumn{1}{c}{ Perceived Barrier Category } & $\begin{array}{c}\text { Number of Times Item } \\
\text { Appeared }\end{array}$ & $\begin{array}{c}\text { \% of Total } \\
(\mathbf{n = 2 2 1})\end{array}$ \\
\hline Lack of time & 48 & $22 \%$ \\
Workload & 22 & $10 \%$ \\
Lack of genuine support/understanding by upper management & 22 & $10 \%$ \\
Unclear and shifting priorities & 22 & $10 \%$ \\
Past experience/cultural baggage & 16 & $7 \%$ \\
Lack of alignment and clear case for change & 16 & $7 \%$ \\
Personal barriers and personal will & 13 & $6 \%$ \\
Exempt/non-exempt, union/management divide & 12 & $5 \%$ \\
Employee resistance & 12 & $5 \%$ \\
Workgroup instability & 9 & $4 \%$ \\
Unsupportive culture & 9 & $4 \%$ \\
No barriers & 9 & $4 \%$ \\
Lack of training & 7 & $3 \%$ \\
Challenges of working globally & 2 & $1 \%$ \\
Generational differences & 2 & $1 \%$ \\
\hline
\end{tabular}

Analysis. In reviewing the list of perceived implementation barriers, it is immediately evident that, while the research has shown that the local manager plays a critical role in creating a high engagement workplace, barriers to engagement cannot be wholly attributed to the skill and/or will of the manager. In the paper "Toward a Multilevel Framework of Engagement and Performance at Work" the authors stress that engagement spans multiple levels and should be examined from a multi-level perspective (Luth \& May, 2012). A social-ecological model provides a useful framework that can be adapted to analyze the list of perceived implementation barriers from a multilevel perspective. Beginning in the 1970s, Urie Bronfenbrenner developed and honed an approach that applies socialecological models to human development. Bronfenbrenner's model defined four major "levels of influence," in which an individual is "nested." These levels; the microsystem, mesosystem, exosystem, and macrosystem; range from the interpersonal realm through macro-cultural influences (Bronfenbrenner, 1979). While Bronfenbrenner recognized the importance of an individual's capabilities and attributes, he believed that individuals are influenced by systems at multiple levels and that these levels are interdependent. In Bronfenbrenner's model, "the properties of the person and of the environment, the structure of the environment setting, and the processes taking place with and between them must be viewed as interdependent and analyzed in systems terms" (Bronfenbrenner, 1979: 41). Bronfenbrenner's model has influenced how researchers and practitioners in many disciplines draw connections between individual behavior and social settings. The model is widely used by the Centers for Disease Control and Prevention (Centers for Disease Control and Prevention, n.d.) and in a variety of related health promotion and prevention projects (Fitzgerald \& Spaccarotella, 2009; Vrazel, Saunders \& Wilcox, 2008).

For the purposes of this analysis, the social-ecological system levels have been adapted and defined as follows: the Individual level, which includes the pattern of skills, knowledge, abilities, and attitudes unique to the individual; the Work Group/Team level, characterized by team structures, processes, and dynamics - including the role and influence of the local manager; the Organization level, defined by the structures, systems, processes, and culture of the organization at large; and, finally, the Macro level, which includes the sector, geographic, social, political, economic, and cultural contexts in which the organization sits (Figure 6). 


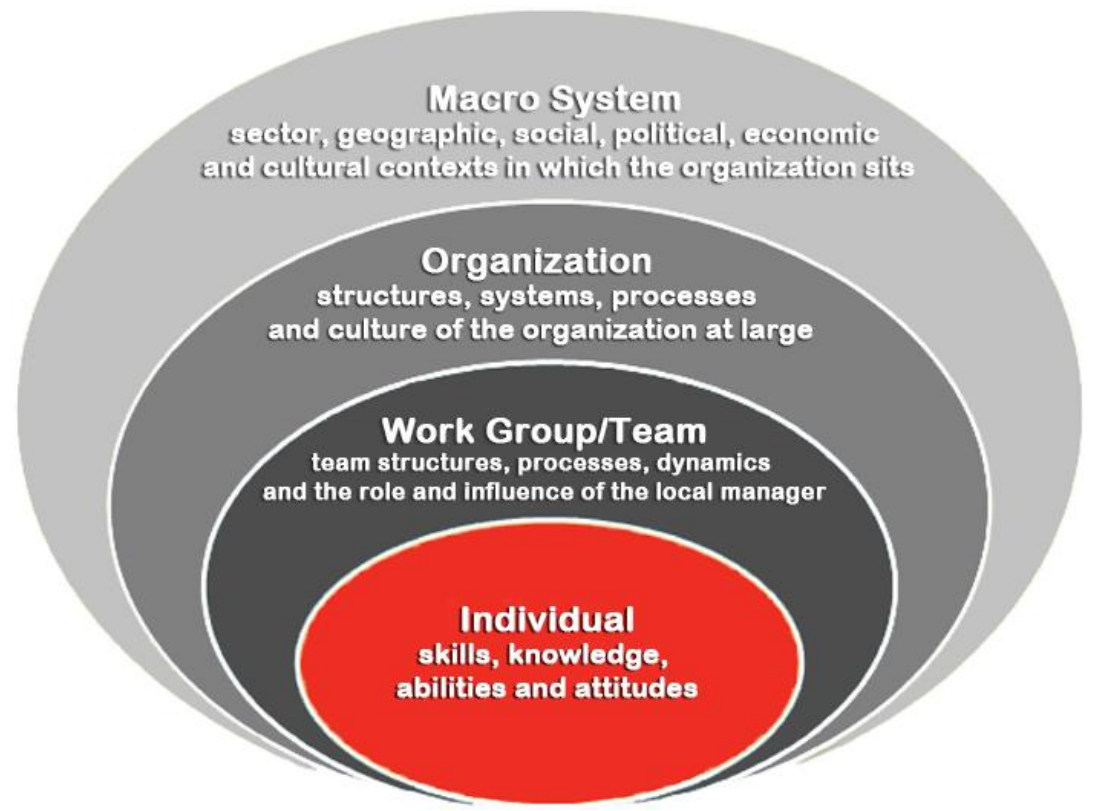

Figure 6. Social Ecological Model

As Bronfenbrenner emphasized, while each level captures a unique perspective, the levels are interdependent and must be analyzed from a systemic perspective (Table 5).

Table 5. Perceived Barrier Categories, System Level Analysis

\begin{tabular}{|c|c|c|c|c|}
\hline Perceived Barrier Category & Individual & $\begin{array}{c}\text { Work } \\
\text { Group/Team }\end{array}$ & Organizational & Macro \\
\hline Lack of time & $\mathrm{X}$ & $\mathrm{X}$ & $\mathrm{X}$ & \\
\hline Workload & $\mathrm{X}$ & $\mathrm{X}$ & $\mathrm{X}$ & \\
\hline Lack of genuine support/understanding by upper management & & $\mathrm{X}$ & $\mathrm{X}$ & \\
\hline Unclear and shifting priorities & & $\mathrm{X}$ & $\mathrm{X}$ & \\
\hline Past experience/cultural baggage & $\mathrm{X}$ & $\mathrm{X}$ & $\mathrm{X}$ & \\
\hline Lack of alignment and clear case for change & & $\mathrm{X}$ & $\mathrm{X}$ & \\
\hline Personal barriers and personal will & $\mathrm{X}$ & & & \\
\hline Exempt/non-exempt, union/management Divide & & $\mathrm{X}$ & $\mathrm{X}$ & \\
\hline Employee resistance & & $\mathrm{X}$ & $\mathrm{X}$ & \\
\hline Workgroup instability & & $\mathrm{X}$ & $\mathrm{X}$ & $\mathrm{X}$ \\
\hline Unsupportive culture & & $\mathrm{X}$ & $\mathrm{X}$ & \\
\hline \multicolumn{5}{|l|}{ No barriers } \\
\hline Lack of training & & $\mathrm{X}$ & $\mathrm{X}$ & \\
\hline Challenges of working globally & $\mathrm{X}$ & $\mathrm{X}$ & $\mathrm{X}$ & $\mathrm{X}$ \\
\hline
\end{tabular}

Conclusion. In reviewing the barrier categories identified, it is immediately evident that focusing on skill building and providing (more) training will not directly impact the root causes that create barriers that mitigate against managers more fully incorporating actions and activities associated with high engagement workplaces into their day to day management practice.

From the list of barriers, it is clear that there are systemic, cultural issues at play that actively discourage management practices that are linked to high engagement workplaces. The important role played by cultural barriers has been long-recognized. Almost thirty years ago, leading management thinker Edward E. Lawler III identified the role played by cultural factors (type of work, complexity of technology, values and beliefs) in influencing engagement (Lawler, 1988). More recently Dave Meslin, a Toronto (Canada)-based artist and community organizer who considers himself a "community choreographer," addressed this in a TED talk. Meslin works across traditional boundaries and sectors to spark engagement in community issues and in his TED talk, "The Antidote to Apathy" (2010), he explores issues related to community engagement and identifies what he calls "a complex web of cultural 
barriers that reinforce disengagement." While Meslin is speaking about community-based engagement, a similar "complex web" exists in many organizational settings. This web of barriers, deeply rooted in the culture of the organization, cannot be effectively addressed by interventions (training or otherwise) aimed only at the individual level but rather must be approached as a cultural change addressing all levels of system aggregation. The concepts discussed in the following section may provide useful approaches for beginning to shift the intervention from the individual to the cultural domain.

\section{CONCLUSIONS AND DISCUSSION}

As the studies presented in the previous sections illustrate, both groups - undergraduate business students who are aspiring managers, and managers - could easily articulate the elements of engagement. Additionally, when asked, managers were able to identify perceived barriers to more fully incorporating these elements into their own management practice. When the social-ecological system framework is used to organize the perceived barrier categories, it is clear that many of the perceived barriers reside at the work group/team and/or organizational system level.

Much of the engagement research and literature identifies the manager as the most important driver of engagement (Baumruk, 2006; Buckingham \& Coffman, 1999; Dale Carnegie Training \& MSW Research, 2012). For example, in their seminal work on engagement, Buckingham and Coffman identify the manager as "the critical player in building a strong workplace" (1999: 32). In the absence of a deeper understanding of system dynamics, these studies and publications lead some organizations to focus engagement interventions exclusively on manager skill development. This pattern is identified in a research brief published by Aberdeen Group, which reported that, "despite the recent enthusiasm for employee engagement, few organizations understand what it is and how it can drive corporate outcomes. In fact, only $23 \%$ of organizations have a formal strategy in place with clear initiatives across the entire organization" (Laurano, 2013: 1). While the manager is undeniably a critical player in the engagement equation, it is manager actions aligned within the integrated context of systemic strategies and approaches that differentiates best practice approaches to engagement.

\section{Recommendations}

While there is clearly an important role for targeted skill development, these investments will not be fully leveraged unless the skill development takes place within the context of other systemic changes. The following sections explore some potentially useful systemic, strategic approaches to cultivating a more deeply rooted, systemic culture of engagement.

Strategy 1: Take a systemic approach to creating a culture of engagement. The pressures driving increased emphasis on employee engagement are systemic in nature, spanning all levels of system aggregation included in the social-ecological model. The Aberdeen Group identifies the three "top pressures for employee engagement" as "growth goals putting focus on productivity and performance," "the need for a more agile workforce," and "concerns over staff retention" (Laurano, 2003: 2). Rather than taking a singular focus on management training and action, addressing these types of pressures requires a comprehensive approach that pays careful attention to the alignment and integration of interventions and action strategies.

The Iceberg Model (Figure 7) provides a useful conceptual framework for the importance of embedding interventions and actions into the unique cultural context of an organization. In this model, the tip of the iceberg above the waterline and clearly visible - represents the "technical" aspects of change, including tangible goals and the application of the array of analytical tools with which most managers and key organizational participants are well-armed. The significantly larger portion of the iceberg - under the waterline and not clearly visible - represents the adaptive or cultural aspects of change; such as beliefs, perceptions, values, and other contextual variables; which represent the unique context within which the desired change must root and flourish. It is the effective interplay of these two aspects that increases the likelihood of successful systemic change initiatives; the technical aspects of the change must be understood, designed, and developed within the unique cultural context of the organization, and the cultural context must be prepared and adapted to support the technical aspects of the change. 


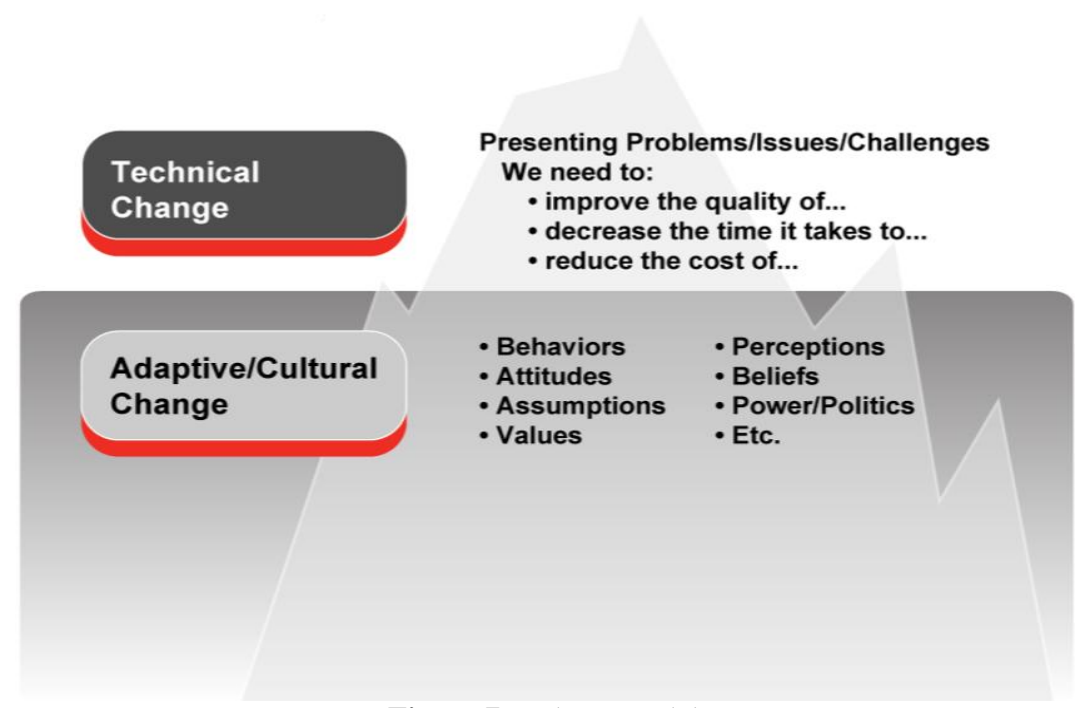

Figure 7. Iceberg Model

The Aberdeen Group also identifies the most common elements of employee engagement employed by best-in-class organizations: employee recognition, cultural values, interaction with direct managers, and work/life balance (in descending order of importance). Interestingly, they also found that "industry average or laggard organizations" are more likely to emphasize interaction with direct managers than best-in-class organizations (Laurano, 2013: 4-5). Leading Through Uncertain Times, a joint research project conducted by World at Work and Towers Watson, produced similar findings. They emphasize the importance of alignment and integration, finding that "organizations with reward and talent management programs that support their business goals are more than twice as likely to report being high-performing companies" (World at Work and Towers Watson, 2011:2). The also report that "those whose programs support the desired culture are more than twice as likely to report having a high-performance work culture" (2). As a part of this conversation, it is important to note that the study conducted by the Aberdeen Group (Laurano, 2013) also identifies the leveraged use of technology as an important strategy. Organizations can use technology to take a more systematic approach to understanding and working with the drivers of employee engagement, moving beyond simple employee surveys to mining the data of performance management and employee self-service portal systems.

These studies provide compelling evidence regarding the importance of taking a systemic approach to creating a high engagement culture that integrates and aligns activities across all levels of system aggregation.

Strategy 2: Make connections to the purpose and deeper meaning of the work. The shifts in the external environment described in the opening sections of this paper have created the need for increased organizational agility. The Aberdeen Group identifies "the need for a more agile workforce" (Laurano, 2013: 2) as the number two pressure driving toward employee engagement. The best-in-class strategies described in the World at Work/ Towers Watson report (2011) echo this theme. This report highlights that these strategies are explicitly designed for agility being able adapt quickly in response to changes in the external environment. The current rapidly changing context creates the need for successful organizations to continually adapt their products, services, and processes - in other words, what they do. With the organizational what in constant flux, the importance of connection to deeper purpose and meaning - the why - is amplified. Organizational purpose can provide a relatively stable foundation and key reference point that can be used to guide the action of organizational participants as they navigate the complexity of internal and external operating environments.

There are decades of literature, from a variety of disciplinary perspectives, that explore various aspects of the gap between knowledge and behavior. One recent contribution to the conversation is The Knowing-Doing Gap by Pfeffer and Sutton. In their book, the authors put forward "eight guidelines for action" $(2000 ; 246)$ that provide a roadmap to effectively narrow the knowing-doing gap. The first of these is, "Why before How: Philosophy is important" (246). In discussing why many companies fail to learn from their efforts to benchmark successful 
companies, they state that, "One reason is that too many managers want to learn 'how' in terms of detailed practices and behaviors and techniques, rather than 'why' in terms of philosophy and general guidance for action" (246). They go on to point out that companies that are successful in adapting to the constantly changing business environment do not focus on a particular set of practices but rather on basic theories, a set of core values, or an underlying philosophy. This approach allows individuals, new and long tenured within the organization, to adapt and take effective action in response to changes in the environment.

The Golden Circle model presented by Simon Sinek in his book, Start with Why (2009), provides a useful conceptual framework for understanding the importance of making connections to purpose and deeper meaning. In his concentric-ring model, Why is at the center, followed by How, then What in the outer-most concentric ring. Sinek contends that most organizations have developed the habit of focusing primarily on What, spend some time on How, and much less time, if any, on Why - in other words, working from the outside in. Sinek suggests this order be flipped: organizations should start with Why, which allows for increased ability to adapt the What to meet the changing demands of the environment and provides a way to engage the passion, interest, and energy of others within and outside the organization.

Making connections to deeper purpose and meaning serves two important roles. Clarity of purpose provides a critical reference point that increases the effectiveness of organizational and individual decision making, and it provides a vibrant source of emotional connection for individuals both inside and outside the organization. Five of the six engagement frameworks discussed in this paper recognize and call forward the important role played by connection to meaning. For example: (1) Wilson Learning highlights the importance of enabling employees to connect to something important (Wilson Learning Worldwide, Inc., n.d.); (2) Gallup's twelve questions emphasize the importance of making connections between mission/purpose and the specifics of an individual's job (Buckingham \& Coffman, 1999); (3) Next Generation Consulting states that passion is unleashed when work has a larger meaning (DiRomualdo, n.d.); and Glassdoor reports that people feel most satisfied with the work when they find it deeply meaningful (Baer, 2013). The importance of connection to purpose and meaning is also reflected in the results of the manager survey discussed above. The category of "meaningful work" was the second most mentioned category, surpassed only by "opportunities to participate."

Leveraging the engagement potential of meaning happens neither automatically nor by accident. Explicitly and strategically making connections for employees between their daily work and larger meaning, "drawing a line of sight," is essential and cannot be left to chance. The Aberdeen Group findings reveal the key differentiator of bestin-class organizations is their ability to communicate core values (and other aspects of engagement efforts) across the organization (Laurano, 2013). There is clearly great engagement potential for making connections to purpose and the deeper meaning of the work, but to realize their potential these efforts must be explicit and systemic, cutting across several levels of system aggregation.

Strategy 3: Tightly integrate development and work. While the focus on management training has likely been overemphasized in the approaches many organizations take toward employee engagement, the ongoing development of the capabilities of managers, especially frontline managers, is indubitably an essential component in successfully developing a high engagement work culture. The critical question revolves around the strategies employed to develop the capabilities of frontline managers. Traditional classroom approaches to training and development typically function almost solely at the Individual level of system aggregation, often limiting the success of long-term behavior change. The limitations of this approach become clear when placed within the context of the social-ecological model. As previously discussed, while individual capabilities and attributes are important, Bronfenbrenner believed individuals are influenced by systems at multiple, interdependent levels: "the properties of the person and of the environment, the structure of the environment setting, and the processes taking place with and between them must be viewed as interdependent and analyzed in systems terms" (1979: 41). The social-ecological model makes a case for the tight integration of development and work activities, keeping individual development within a context of other levels of system aggregation.

The white paper, entitled "Future Trends in Leadership Development" and published by the Center for Creative Leadership, frames a focus on development solely at the Individual level as "horizontal development." Horizontal development; the development of new skills, abilities, and behaviors; is "most useful when a problem is 
clearly defined and there are known techniques for solving it" (Petrie, 2011: 11). Developing the capacity to engage employees in complex internal and external operating environments requires making changes at the cultural adaptive level. When working in this context, horizontal development strategies will not suffice.

The SHRM Foundation's report (Day, 2007) on developing leadership talent includes a comprehensive discussion of leadership development practices. The report states that a "major way in which developmental practices differ is in terms of how embedded each practice is in the ongoing work context" (23). Their research also finds that classroom programs (a method that is, at best, only minimally embedded in the ongoing work context) "continue to be the backbone of most leadership development initiatives" (23). At the other end of the spectrum is action learning, defined as "an approach that is based on the assumption from adult learning theory that people learn most effectively when working on organizational problems in real time" (27). The SHRM Foundation reports that research by Linkage, Inc. found "the most developmentally potent component of leadership development initiatives is action learning" (29).

When exploring the gap between knowing what to do and actually doing it, Pfeffer and Sutton recommend embedding "more of the process of acquiring new knowledge in the actual doing of the task and less in formal training programs that are frequently ineffective" (2000: 27) and note that this practice is "rarely followed." The second of their "eight guidelines for action" is, "knowing comes from doing and teaching others how" (248).

While there is clearly a need (for a variety of reasons) for the on-going and active development of managers, these efforts are often misguided. The large magnitude investment made by U.S. organizations in the training and development of individuals would yield more significant results if it were focused more on action learning projects - those that cut across all levels of system aggregation - and less on classroom training initiatives.

Summary. As internal and external environments become increasingly complex and shifts in fundamental demographic patterns continue to intensify, employee engagement has become a key strategy for many organizations. While the importance of engagement is well-understood, the same cannot be said for effective intervention strategies aimed at increasing levels of engagement. Most companies intervene solely at the individual level of system aggregation and rely too heavily on traditional training approaches. Best-in-class companies have come to realize that, while there is a role of individual skill development, effective engagement strategies are systemic and integrate a focus on all levels of system aggregation.

The strength of this small, yet disciplined, qualitative research study is that it integrates a wide variety of frameworks and models, both practical and theoretical, into a cohesive exploratory conversation. In doing so, it makes a contribution to the understanding of effective, practical implementation approaches that are of strategic importance to many organizations. It also sets the stage for future research studies focused on the gap between knowledge and behavior. The study was limited in that it primarily focused on the perceptions of the managers related to the gap between knowledge and behavior. While understanding the perceptions of the managers is essential (perceptions drive behavior) their perceptions may be somewhat skewed by fundamental attribution bias. Building on this work, future studies should round out the picture by drawing upon the larger body of training transfer literature.

\section{AUTHOR INFORMATION}

Dr. Fredricka F. Joyner has been with Indiana University for the past thirteen years and is currently an Associate Professor at the Indiana University East School of Business and Economics where she directs the IU East Center for Leadership Development and the Master's in Management program. She has won a number of awards for her teaching and is an active researcher with numerous publications. In her active consulting practice, Dr. Joyner focuses on unleashing the potential of leaders, organizations, and communities. 


\section{REFERENCES}

Ahlrichs, N. 2003. Manager of choice: Five competencies for cultivating top talent. Palo Alto, CA: Davies-Black Publishing.

Ames, K. 2012. Loyalty, productivity and advocacy: 3 characteristics of employee engagement. January. Retrieved from http://www.octanner.com

Baer, D. 2013. The 6 secrets of America's happiest workplaces. December 11. Retrieved from www.fastcompany.com/3023191/

Baumruk, R. 2006. Why managers are crucial to increasing engagement: Identifying steps managers can take to engage their workforce. Strategic HR Review, 5(2): 24-27.

Bronfenbrenner, U. 1979. The ecology of human development: Experiments by nature and design. Cambridge, MA: Harvard University Press.

Buckingham, M. \& Coffman, C. 1999. First, break all the rules. New York: Simon \& Schuster.

Business Week. 2008. Toxic bosses: How to live with the S.O.B. August: 48.

Centers for Disease Control and Prevention. n.d. The social-ecological model: A framework for prevention. Retrieved January 28, 2013, from http://www.cdc.gov/

Corporate Executive Board. 2004. Driving employee performance and retention through engagement. Retrieved from http://www.usc.edu/programs/cwfl/assets/pdf/ Employee\%20engagement.pdf

Corporate Executive Board. 2010. Report on The role of employee engagement in the return to growth.

Dale Carnegie Training \& MSW Research. 2012. What drives employee engagement and why it matters. Retrieved from http://www.dalecarnegie.com

Day, D. V. 2007. Developing leadership talent. Alexandria, VA: SHRM Foundation.

DiRomualdo, T. n.d. The next generation company. Next Generation Consulting, Inc. Retrieved March 26, 2005, from http://www.nextgenerationcompany.com

Employment Policy Foundation. 2001. Future labor and skills shortages jeopardize American prosperity. Employment Forecast: Contemporary Issues in Employment and Workplace Policy. Retrieved from http://web.archive.org/web/20030405060947/ http://epf.org/ research/newsletters/2001/ef20011025.pdf

European Commission. n.d. Demographic analysis - Employment, social affairs \& inclusion. Retrieved January 23, 2014, from http://ec.europa.eu/social/

European Commission. 2011. Demography report 2010: Older, more numerous and diverse Europeans. Retrieved from http://ec.europe.eu/social/

Feinberg, J. 2011. Wordle: Beautiful word clouds. Retrieved from http://www.wordle.net

Fishman, C. 1998. The war for talent. July 31. Retrieved from http://www.fastcompany.com /magazine/16/mckinsey.html

Fitzgerald, N. \& Spaccarotella, K. 2009. Barriers to a healthy lifestyle: From individuals to public policy - An ecological perspective. Journal of Extension, 47(1) Article 1FEA3. Retrieved from http://www.joe.org/joe/2009february/a3.php

Harris, T. 2008. Using personality data to identify and develop high-potential leaders. Talent Management. January. Retrieved from http://talentmgt.com/articles/

Hollon, John. 2013. New study: Spending on training jumped by $12 \%$ last year. TLNT. January 23. Retrieved from http://www.tlnt.com/2013/

Klavan, E. 1990. Finding a cure for a toxic boss. Woman's Day, 53(5): 52-53.

Krueger, J. \& Killham, E. 2006. Why Dilbert is right. Gallup Management Journal. March 9. Retrieved from http://businessjournal.gallup.com/content/21802/why-dilbert-is-right.aspx

Kruse, K. 2012. What is employee engagement. Forbes Online. June. Retrieved from http://www.forbes.com/sites/kevinkruse/2012/

Kusy, M. \& Holloway, E. 2009. Toxic workplace!: Managing toxic personalities and their systems of power. San Francisco, CA: John Wiley \& Sons.

Laurano, M. 2013. The age of employee engagement. Aberdeen Group Research Reports. September 17. Retrieved from http://www.aberdeen.com/Aberdeen-Library/8648/RB-employee-engagement-strategies.aspx

Lawler III, E.E. 1988. Choosing an involvement strategy. Academy of Management Executive, 2(3): 197 - 204.

Lupfer, E. 2013. Ten Employee engagement ideas that get serious results. Social Media Today. September. Retrieved from http://www.socialmediatoday.com

Luth, M.T. \& May, D.R. 2012. Toward a multilevel framework of engagement and performance at work. Academy 
of Management Annual Meeting Proceedings. Retrieved from http://web.a.ebscohost.com.proxy.library.iue.

Management Study Guide. n.d. Characteristics of engaged workforce. Retrieved December 31, 2013, from http://www.managementstudyguide.com/

Meslin, D. 2010. The antidote to apathy. In TEDxToronto (Producer), TED. Retrieved from http://www.ted.com/talks/dave_meslin_the_antidote_to_apathy.html

Miller, L. 2012. ASTD state of the industry report: Organizations continue to invest in workplace learning. November 8. Retrieved from http://www.astd.org/Publications /Magazines/TD/

O'Boyle, E. \& Harter, J. 2013. State of the American workplace: Employee engagement insights for U.S. business leaders. Washington, D.C.: Gallup.

Petrie, N. 2011. Future trends in leadership development. Greensboro, NC: Center for Creative Leadership.

Pfeffer, J. \& Sutton, R.I. 2000. The knowing-doing gap: How smart companies turn knowledge into action. Boston, MA: Harvard Business School Press.

Right Management. 2013. Spending on leadership programs expected to rise. July 29. Retrieved from http://www.right.com/news-and-events/press-releases/

Roberts, R. \& Johnson, T. 2010. Dealing with a toxic boss [Good Morning America, America's Jobs segment]. October 28. In ABC News (Producer). New York, NY: American Broadcasting Company.

Rucci, A. J., Kirn, S. P., \& Quinn, R. T. 1998. The employee-customer-profit chain at Sears. Harvard Business Review, 76(1): 82-97.

Ryan Group Inc. n.d. Employee engagement assessment. Retrieved December 31, 2013, from http://www.ryangroup.contentshelf.com/

Schmidt, A. A. 2008. Development and validation of the toxic leadership scale (Master's thesis). Retrieved from Digital Repository at the University of Maryland. (UMI 1453699)

Scholtes, P. R. 1998. The leader's handbook: A guide to inspiring your people and managing the daily workflow. New York: McGraw-Hill.

Sidle, S.D. 2009. Is your organization a great place for bullies to work? Academy of Management Perspectives, 23(4): $89-91$.

Sinek, S. 2009. Start with why: How great leaders inspire everyone to take action. New York: PORTFOLIO/Penguin.

Vrazel, J., Saunders, R. \& Wilcox, S. 2008. An overview and proposed framework of social-environmental influences on the physical-activity behavior of women. American Journal of Health Promotion, 23(1): 212.

Williams, R. 2010. Employee engagement: Define it, measure it, and put it to work in your organization. January. Retrieved from http://www.workforce.com/articles/employee-engagement-define-it-measure-it-and-put-itto-work-in-your-organization

Wilson Learning Worldwide Inc. n.d. Employee engagement: The leader's role. Edina, MN: Wilson Learning Worldwide Inc.

World at Work \& Towers Watson. 2011. The talent management and rewards imperative for 2012: Leading through uncertain times. Retrieved from http://www.worldatwork.org /waw/ 